\title{
Effects of Breathing Pattern on Oxygen Delivery Via a Nasal or Pharyngeal Cannula
}

\author{
Natsuhiro Yamamoto MD, Tetsuya Miyashita MD, Shunsuke Takaki MD, and Takahisa Goto MD
}

\begin{abstract}
BACKGROUND: During sedation for upper gastrointestinal endoscopy, oxygen delivery via a nasal cannula is often necessary. However, the influences of the oxygen delivery route and breathing pattern on the $\mathrm{F}_{\mathrm{IO}_{2}}$ have not been thoroughly investigated. The aim of this simulation study was to investigate the difference in the $\mathrm{F}_{\mathrm{IO}_{2}}$ with a pharyngeal cannula versus nasal cannula during highor low-tidal volume $\left(V_{T}\right)$ ventilation and open- or closed-mouth breathing. METHODS: Six healthy volunteers were asked to breathe using 2 patterns of ventilation (high or low $V_{T}$ ) via a sealed face mask connected to an endotracheal tube that was retrogradely inserted into the trachea of a mannequin. The mannequin also had a pharyngeal or nasal cannula inserted into the pharynx or attached to the nose, through which oxygen $(2$ or $5 \mathrm{~L} / \mathrm{min})$ was delivered. The mouth of the mannequin was kept open or closed by packing. We measured the $\mathrm{F}_{\mathrm{IO}_{2}}$ of every breath for 1 min at each setting. RESULTS: During low- and high- $\mathrm{V}_{\mathrm{T}}$ ventilation, the $\mathrm{F}_{\mathrm{IO}_{2}}$ was highest at a flow of $5 \mathrm{~L} / \mathrm{min}$ with a pharyngeal cannula. Oxygen delivery was higher with the pharyngeal cannula compared with the nasal cannula at all settings. Differences in flow did not result in significant differences in the $\mathrm{F}_{\mathrm{IO}_{2}}$ with high- and low- $\mathrm{V}_{\mathrm{T}}$ ventilation. At a flow of $5 \mathrm{~L} / \mathrm{min}$ via a pharyngeal cannula, open-mouth breathing resulted in a significantly higher $\mathrm{F}_{\mathrm{IO}_{2}}$ compared with closed-mouth breathing. Conclusions: A pharyngeal cannula provided a higher $\mathrm{F}_{\mathrm{IO}_{2}}$ compared with a nasal cannula at the same oxygen flow. Open-mouth breathing resulted in a higher $\mathrm{F}_{\mathrm{IO}_{2}}$ compared with closed-mouth breathing when $5 \mathrm{~L} / \mathrm{min}$ oxygen was delivered via a pharyngeal cannula. The breathing pattern did not affect the $\mathbf{F}_{\mathrm{IO}_{2}}$ in this study. Key words: nasal cannula; pharyngeal cannula; oxygen delivery; simulation study. [Respir Care 2015;60(12):1804-1809. (c) 2015 Daedalus Enterprises]
\end{abstract}

\section{Introduction}

During procedural sedation for upper gastrointestinal endoscopy or any other invasive procedure, oxygen delivery via a nasal cannula is frequently necessary to prevent hypoxia. However, according to American Thoracic Society recommendations, the oxygen flow of a nasal cannula is limited to $5 \mathrm{~L} / \mathrm{min}^{1}$

The authors are affiliated with the Department of Anesthesiology, Yokohama City University Hospital, Yokohama, Japan.

The authors have disclosed no conflicts of interest.

Correspondence: Tetsuya Miyashita MD, Department of Anesthesiology, Yokohama City University Hospital, 3-9 Fukuura Kanazawa, Yokohama City 236-0004, Japan. E-mail: yushukyo@ gmail.com.

DOI: $10.4187 /$ respcare. 04173
Generally, an oxygen flow of $5 \mathrm{~L} / \mathrm{min}$ can provide an $\mathrm{F}_{\mathrm{IO}_{2}}$ of no more than 0.50. ${ }^{2-4}$ Besides oxygen flow, the $\mathrm{F}_{\mathrm{IO}_{2}}$ depends on several other factors, such as breathing pattern and volume of the oral cavity as an oxygen reservoir. Additionally, sedative drugs have been shown to induce changes in the breathing pattern. Opioids cause high-tidal volume $\left(\mathrm{V}_{\mathrm{T}}\right)$ and low-breathing frequency patterns. ${ }^{5}$ Benzodiazepines and propofol cause low- $\mathrm{V}_{\mathrm{T}}$ and high-breathing frequency patterns. ${ }^{6,7}$ Although some reports have measured the $\mathrm{F}_{\mathrm{IO}_{2}}$ during oxygen delivery via a nasal cannula, ${ }^{2,4,8}$ the influence of breathing pattern on the $\mathrm{F}_{\mathrm{IO}_{2}}$ has not been investigated.

Oxygen delivery via a pharyngeal cannula results in the oxygen being placed closer to the trachea compared with a nasal cannula. It has been suggested that use of a pharyngeal cannula may provide a higher $\mathrm{F}_{\mathrm{IO}_{2}} \cdot{ }^{9}$

The $\mathrm{F}_{\mathrm{IO}_{2}}$ also depends on whether the mouth of the patient is open or closed while breathing. Some studies found no significant difference in the $\mathrm{F}_{\mathrm{IO}_{2}}$ between open- 
and closed-mouth breathing, 2,10 whereas another study found higher oxygen fractions during open-mouth versus closed-mouth breathing. ${ }^{4}$

The aim of this simulation study was to investigate the changes in the $\mathrm{F}_{\mathrm{IO}_{2}}$ during high- and low- $\mathrm{V}_{\mathrm{T}}$ ventilation when oxygen is provided via a pharyngeal cannula rather than a nasal cannula using a mannequin and spontaneously breathing healthy volunteers.

\section{Methods}

The local ethics committee approved this study, and we obtained written informed consent from each subject. Six healthy volunteers (25-48 y old) participated in this study. Each participant was asked to breathe using 2 patterns of ventilation: high $\mathrm{V}_{\mathrm{T}}(700-800 \mathrm{~mL}$, breathing frequency of 12 breaths/min, and inspiratory-expiratory ratio of $1: 1$ and low $\mathrm{V}_{\mathrm{T}}(350-400 \mathrm{~mL}$, breathing frequency of 24 breaths $/ \mathrm{min}$, and inspiratory-expiratory ratio of 1:1 via a sealed face mask connected to an endotracheal tube (8.0-mm inner diameter, Hi-Lo tracheal tube, Mallinckrodt, NeunkirchenSeelscheid, Germany) that was retrogradely inserted into the trachea of a mannequin (SimMan, Laerdal Medical, Stavanger, Norway) (Fig. 1). $V_{T}$ was measured with a flow meter (Haloscale standard respirometer, Wright, United Kingdom) placed near the face mask. The mouth of the mannequin was opened or closed by packing and sealing. After a nasal cannula was attached to the mannequin's nose or an 8 French pharyngeal cannula was inserted through the nose into its pharyngeal space, the oxygen flow was adjusted to 2 or $5 \mathrm{~L} / \mathrm{min}$. In addition, for the pharyngeal cannula, an oxygen flow of $10 \mathrm{~L} / \mathrm{min}$ was also studied to measure the maximum $\mathrm{F}_{\mathrm{IO}_{2}}$ in an emergency setting. Before the start of each measurement, participants were asked to breathe for $>3 \mathrm{~min}$ as preparation to stabilize the $\mathrm{F}_{\mathrm{IO}_{2}}$. We used a gas analyzer (AG-920R multigas unit, Nihon Kohden, Tokyo, Japan) to measure the $\mathrm{F}_{\mathrm{IO}_{2}}$ of every breath by obtaining samples from near the sealed face mask using a side-flow method for $1 \mathrm{~min}$ at each setting. With this method, the $\mathrm{F}_{\mathrm{IO}_{2}}$ of exhaled gas could be distinguished from that of inhaled gas. Following data collection for $1 \mathrm{~min}$, each participant was asked to breathe at a new setting. This process was repeated at oxygen flows of 2 and $5 \mathrm{~L} / \mathrm{min}$ (Fig. 2). After an interval of $>30$ min, the same process was repeated with other oxygen supply devices (nasal or pharyngeal cannula), position of mouth (open or closed), and breathing patterns (high or low $\mathrm{V}_{\mathrm{T}}$ ).

The data for the $\mathrm{F}_{\mathrm{IO}_{2}}$ at each setting were expressed as mean $\pm \mathrm{SD}$ and analyzed by 2-way analysis of variance and the Tukey test as a post hoc test using SPSS (SPSS, Chicago, Illinois). $P<.05$ was considered statistically significant.

\section{QUICK LOOK}

\section{Current knowledge}

Low-flow oxygen is commonly delivered using a nasal cannula at a flow $<6 \mathrm{~L} / \mathrm{min}$. In this flow range, patient breathing pattern can impact the delivered $\mathrm{F}_{\mathrm{IO}_{2}}$. The pharyngeal catheter is not commonly used owing to issues of patient discomfort. Low-flow oxygen therapy with any appliance is complicated by changes in tidal volume and breathing frequency.

\section{What this paper contributes to our knowledge}

In a model system, a pharyngeal catheter provided higher $\mathrm{F}_{\mathrm{IO}_{2}}$ than a nasal cannula at the same oxygen flow. Open-mouth breathing resulted in a higher $\mathrm{F}_{\mathrm{IO}_{2}}$ than closed-mouth breathing when $5 \mathrm{~L} / \mathrm{min}$ oxygen was delivered via a pharyngeal catheter. The breathing pattern did not affect $\mathrm{F}_{\mathrm{IO}_{2}}$ in this study.

\section{Results}

In this study, the volume of the space from the retrogradely intubated tube to the face mask was $\sim 60 \mathrm{~mL}$. All participants could breathe as expected.

\section{Pharyngeal Versus Nasal Cannula}

With open-mouth low- and high- $\mathrm{V}_{\mathrm{T}}$ ventilation settings, the $\mathrm{F}_{\mathrm{IO}_{2}}$ was highest with a pharyngeal cannula at a flow of $5 \mathrm{~L} / \mathrm{min}(0.63 \pm 0.06$ and $0.64 \pm 0.07$, respectively) and lowest with a nasal cannula at a flow of $2 \mathrm{~L} / \mathrm{min}(0.32 \pm$ 0.02 and $0.32 \pm 0.02$, respectively) (Figs. 3 and 4). This trend was also observed with closed-mouth settings (Figs. 5 and 6). At the same oxygen flow with open-mouth settings, the pharyngeal cannula $\left(0.38 \pm 0.04\right.$ at low $\mathrm{V}_{\mathrm{T}}$ and $0.39 \pm 0.05$ at high $\mathrm{V}_{\mathrm{T}}$ with $2 \mathrm{~L} / \mathrm{min}$ oxygen, $0.63 \pm$ 0.06 at low $\mathrm{V}_{\mathrm{T}}$ and $0.64 \pm 0.07$ at high $\mathrm{V}_{\mathrm{T}}$ with $5 \mathrm{~L} / \mathrm{min}$ oxygen) showed a significantly higher $\mathrm{F}_{\mathrm{IO}_{2}}$ than the nasal cannula $\left(0.32 \pm 0.02\right.$ at low $\mathrm{V}_{\mathrm{T}}$ and $0.32 \pm 0.02$ at high $\mathrm{V}_{\mathrm{T}}$ with $2 \mathrm{~L} / \mathrm{min}$ oxygen, $0.51 \pm 0.06$ at low $\mathrm{V}_{\mathrm{T}}$ and $0.54 \pm 0.05$ at high $\mathrm{V}_{\mathrm{T}}$ with $5 \mathrm{~L} / \mathrm{min}$ oxygen, $P<$ .05 ). This was also true with closed-mouth settings (pharyngeal cannula: $0.36 \pm 0.04$ at low $\mathrm{V}_{\mathrm{T}}$ and $0.38 \pm 0.05$ at high $\mathrm{V}_{\mathrm{T}}$ with $2 \mathrm{~L} / \mathrm{min}$ oxygen, $0.57 \pm 0.07$ at low $\mathrm{V}_{\mathrm{T}}$ and $0.61 \pm 0.08$ at high $\mathrm{V}_{\mathrm{T}}$ with $5 \mathrm{~L} / \mathrm{min}$ oxygen; nasal cannula: $0.33 \pm 0.03$ at low $\mathrm{V}_{\mathrm{T}}$ and $0.32 \pm 0.04$ at high $\mathrm{V}_{\mathrm{T}}$ with $2 \mathrm{~L} / \mathrm{min}$ oxygen, $0.49 \pm 0.06$ at low $\mathrm{V}_{\mathrm{T}}$ and $0.51 \pm 0.08$ at high $\mathrm{V}_{\mathrm{T}}$ with $5 \mathrm{~L} / \mathrm{min}$ oxygen, $P<.05)$.

With both low- and high- $\mathrm{V}_{\mathrm{T}}$ settings during openmouth breathing, the $\mathrm{F}_{\mathrm{IO}_{2}}$ at a flow of $5 \mathrm{~L} / \mathrm{min}$ via a 

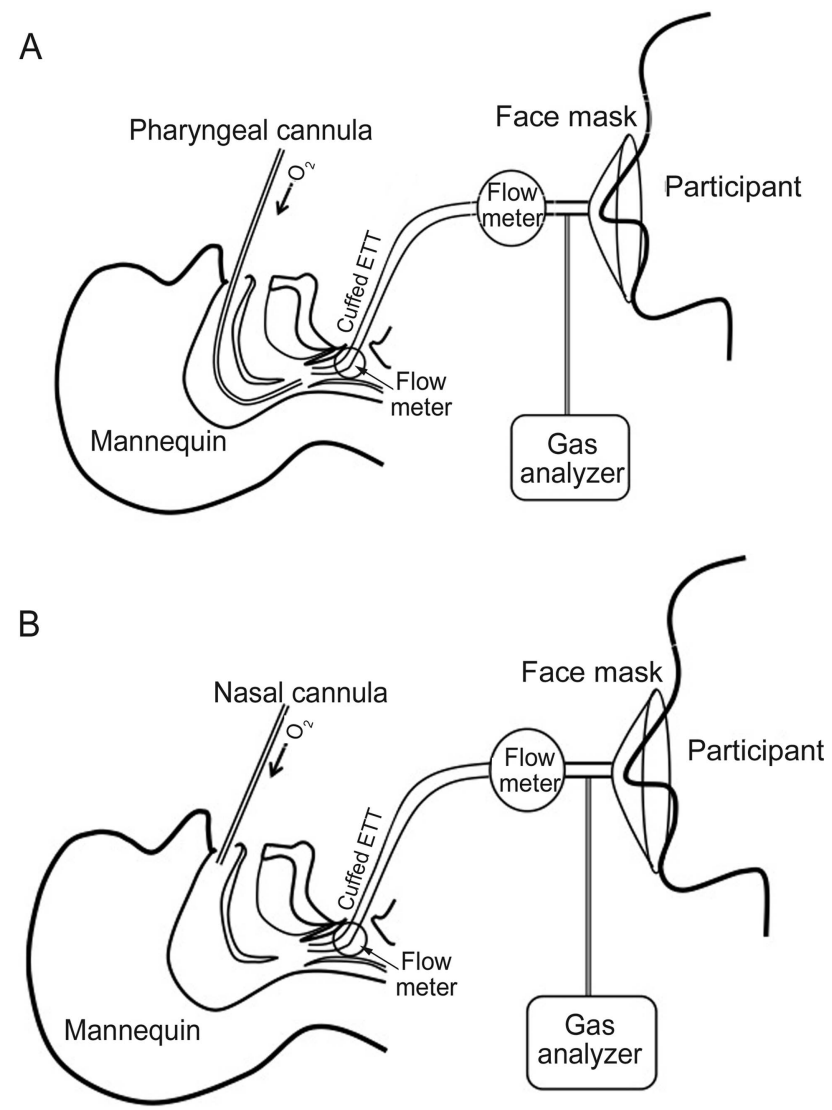

Fig. 1. An endotracheal tube (ETT) was retrogradely inserted into the trachea of a mannequin. The proximal end of the tube was connected to a sealed face mask via a flow meter. A pharyngeal $(A)$ or nasal $(B)$ cannula was used for oxygen delivery to the mannequin.

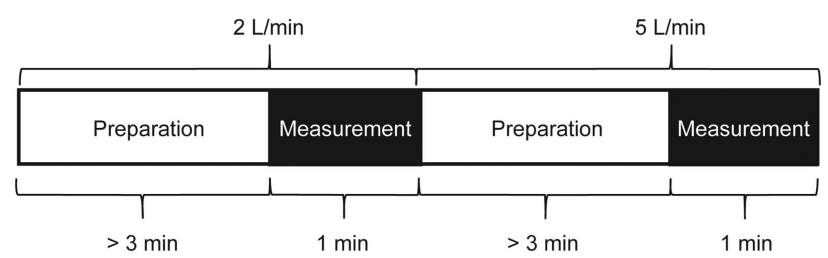

Fig. 2. First, oxygen flow was adjusted to $2 \mathrm{~L} / \mathrm{min}$. Before the start of each measurement, each subject was asked to breathe for $>3$ min as preparation to stabilize the $\mathrm{F}_{\mathrm{IO}_{2}}$. The $\mathrm{F}_{\mathrm{IO}_{2}}$ of every breath was measured for $1 \mathrm{~min}$ in each setting. Following data collection for $1 \mathrm{~min}$, flow was adjusted to $5 \mathrm{~L} / \mathrm{min}$, and the same process (preparation and measurement) was repeated. After an interval of $>30 \mathrm{~min}$, the same course with other oxygen supply devices (nasal or pharyngeal cannula), position of mouth (open or closed), and breathing patterns (high or low tidal volume) was repeated.

nasal cannula $(0.51 \pm 0.06$ for a low tidal setting, $0.54 \pm$ 0.05 for a high tidal setting) was significantly higher than that at a flow of $2 \mathrm{~L} / \mathrm{min}$ via a pharyngeal cannula $(0.39 \pm 0.05$ for a high tidal setting, $0.38 \pm 0.04$ for a low tidal setting, $P<.01$ ). This was also true with closed-mouth settings.

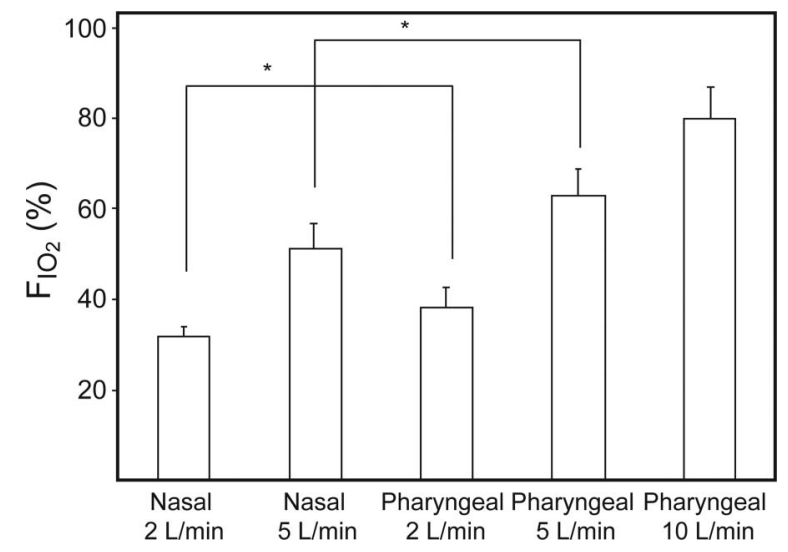

Fig. 3. Comparison of the $\mathrm{F}_{\mathrm{IO}_{2}}$ at low tidal volume $(350-400 \mathrm{~mL})$ with open-mouth breathing at the different study settings. ${ }^{*} P<.05$.

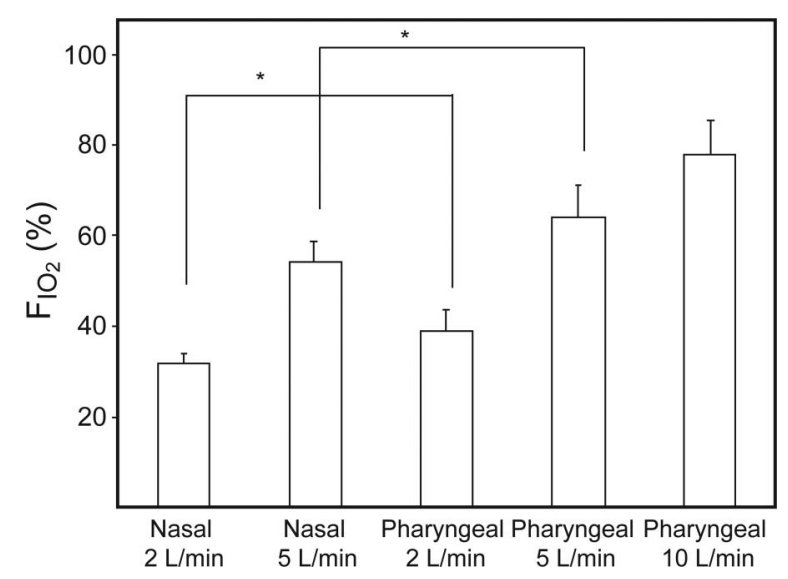

Fig. 4. Comparison of the $\mathrm{F}_{1 \mathrm{O}_{2}}$ at high tidal volume $(700-800 \mathrm{~mL})$ with open-mouth breathing at the different study settings. ${ }^{*} P<.05$.

\section{High Versus Low $V_{T}$}

With both nasal and pharyngeal cannulas and the openand closed-mouth settings, $\mathrm{V}_{\mathrm{T}}$ had no effect on the $\mathrm{F}_{\mathrm{IO}_{2}}$ at the same oxygen flow (Figs. 7 and 8).

\section{Open Versus Closed Mouth}

Open-mouth breathing resulted in a significantly higher $\mathrm{F}_{\mathrm{IO}_{2}}$ than closed-mouth breathing when using the pharyngeal cannula at low $\mathrm{V}_{\mathrm{T}}(0.38 \pm 0.04$ vs $0.36 \pm 0.04$ with $2 \mathrm{~L} / \mathrm{min}$ oxygen, $P=.02 ; 0.63 \pm 0.06$ versus $0.57 \pm 0.07$ with $5 \mathrm{~L} / \mathrm{min}$ oxygen, $P<.01$ ). During high- $\mathrm{V}_{\mathrm{T}}$ ventilation, a significant difference was observed only with 5 L/min oxygen: $0.32 \pm 0.02$ vs $0.32 \pm 0.04$ with $2 \mathrm{~L} / \mathrm{min}$ oxygen (the difference was not significant) and $0.64 \pm$ 0.07 vs $0.61 \pm 0.08$ with $5 \mathrm{~L} / \mathrm{min}$ oxygen $(P=.04)$ (Figs. 9 and 10). With low- and high- $\mathrm{V}_{\mathrm{T}}$ ventilation settings and open- and closed-mouth breathing, $10 \mathrm{~L} / \mathrm{min}$ oxygen flow via a pharyngeal cannula provided the highest oxygen frac- 


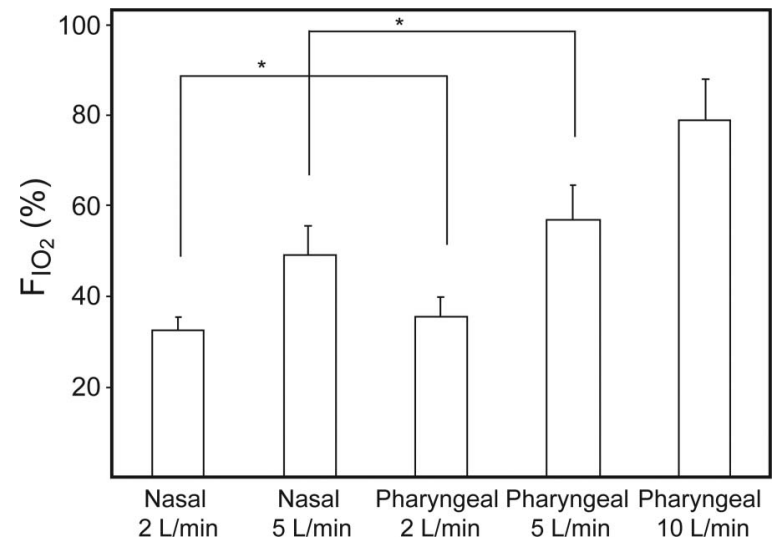

Fig. 5. Comparison of the $\mathrm{F}_{\mathrm{IO}_{2}}$ at low tidal volume $(350-400 \mathrm{~mL})$ with closed-mouth breathing at the different study settings. ${ }^{*} P<.05$.

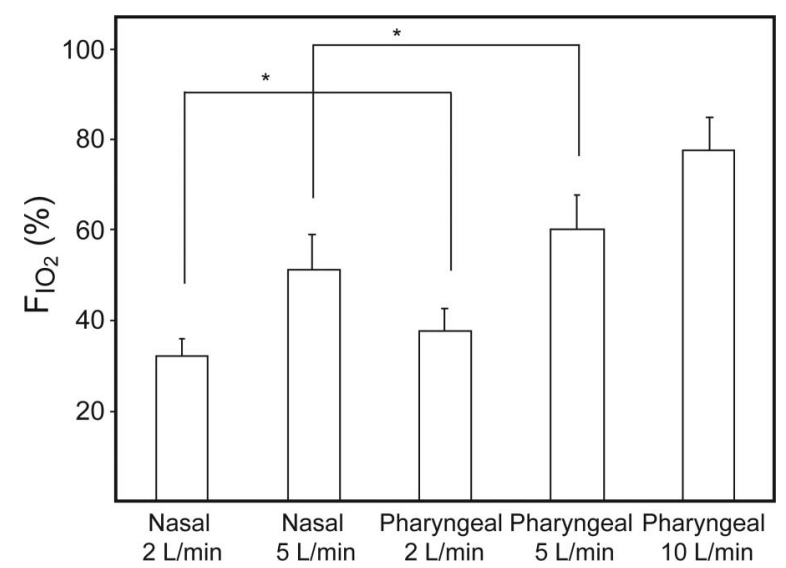

Fig. 6. Comparison of the $\mathrm{F}_{\mathrm{IO}_{2}}$ at high tidal volume $(700-800 \mathrm{~mL})$ with closed-mouth breathing at the different study settings. ${ }^{*} P<.05$.

tion $(0.80 \pm 0.07$ and $0.78 \pm 0.07$ with open-mouth breathing, $0.79 \pm 0.09$ and $0.78 \pm 0.07$ with closed-mouth breathing) (Table 1).

\section{Discussion}

In this study, we found that a pharyngeal cannula provided a higher $\mathrm{F}_{\mathrm{IO}_{2}}$ than a nasal cannula at the same oxygen flow during both open- and closed-mouth breathing. Compared with a nasal cannula, oxygen was delivered close to the trachea with a pharyngeal cannula, thus minimizing dilution of the oxygen with air. Eastwood et $\mathrm{al}^{9}$ reported that nasopharyngeal oxygen supplementation via a 10 French catheter inserted just behind the soft palate required a lower oxygen flow compared with a face mask to maintain oxygen saturation. Transtracheal catheters were also reported to be more effective than nasal cannulas at the same oxygen flow in a previous study. ${ }^{3}$

In addition, the cavity of the pharynx serves as a large oxygen reservoir in the pharyngeal cannula setting. The

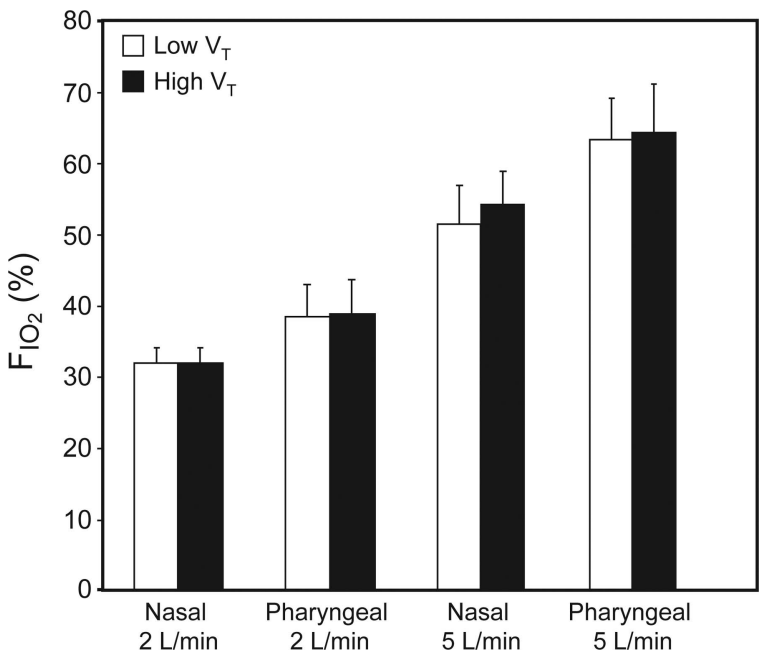

Fig. 7. Comparison of the $\mathrm{F}_{\mathrm{IO}_{2}}$ at low $(350-400 \mathrm{~mL})$ and high (700-800 $\mathrm{mL}$ ) tidal volumes $\left(\mathrm{V}_{\mathrm{T}}\right)$ with open-mouth breathing. No significant difference was observed between low- and high- $\mathrm{V}_{\mathrm{T}}$ ventilation at the same flow and with the same oxygen supply device (nasal or pharyngeal cannula).

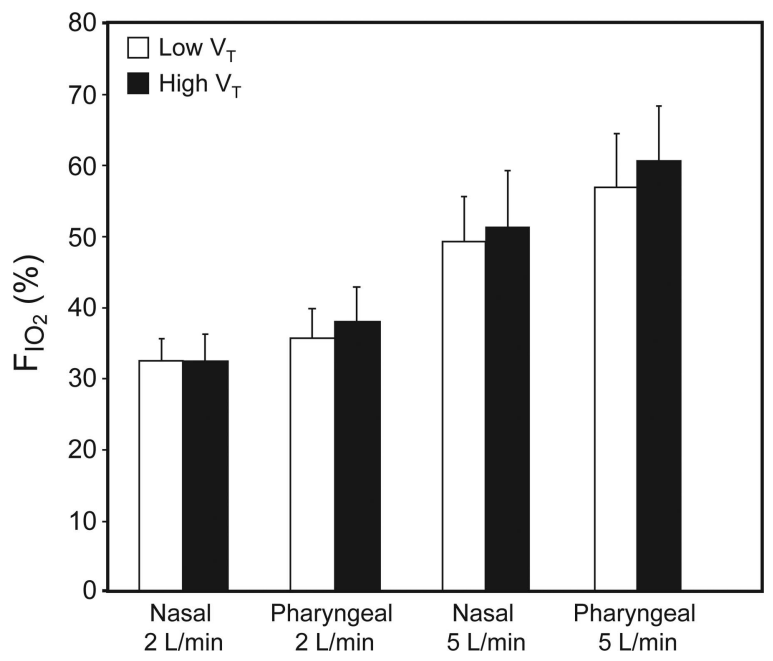

Fig. 8. Comparison of the $\mathrm{F}_{\mathrm{IO}_{2}}$ at low $(350-400 \mathrm{~mL})$ and high $(700-800 \mathrm{~mL})$ tidal volumes $\left(\mathrm{V}_{\mathrm{T}}\right)$ with closed-mouth breathing. No significant difference was observed between low- and high- $\mathrm{V}_{\mathrm{T}}$ ventilation at the same flow and with the same oxygen supply device (nasal or pharyngeal cannula).

size of the reservoir might also affect the difference in the $\mathrm{F}_{\mathrm{IO}_{2}}$ between nasal and pharyngeal cannulas. Whether the mouth was open or closed during supplemental oxygen administration was previously reported to affect the $\mathrm{F}_{\mathrm{IO}_{2}}$. Wettstein et $\mathrm{al}^{4}$ reported that the $\mathrm{F}_{\mathrm{IO}_{2}}$ was significantly higher with an open mouth compared with a closed mouth in healthy volunteers with nasal cannulas. Kory et al $^{10}$ reported that open-mouth breathing resulted in oxygen concentrations similar to or higher than those obtained with closed-mouth breathing. These reports all speculated that the larger oral cavity resulted in an increase in 


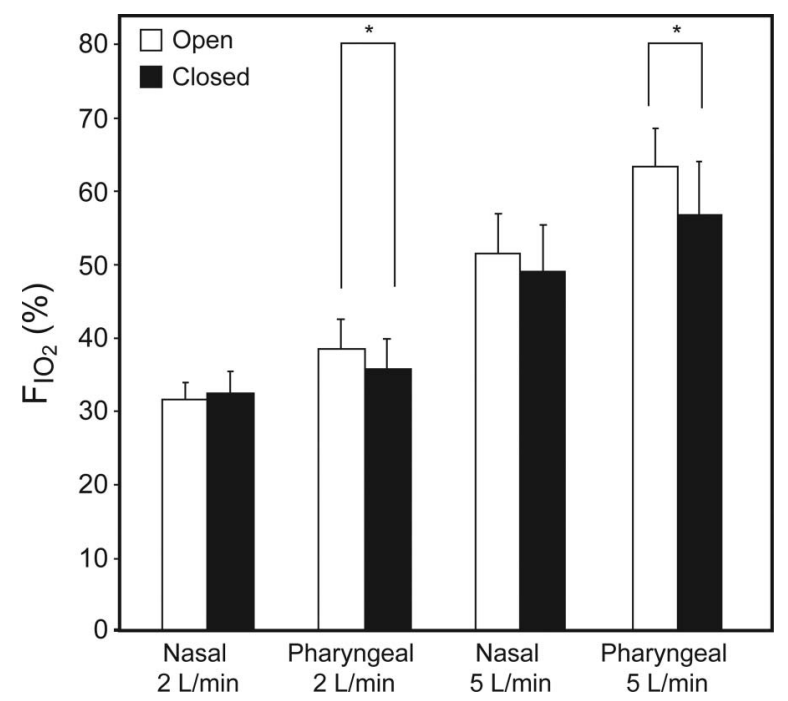

Fig. 9. Comparison between open- and closed-mouth breathing at a low tidal volume. Open-mouth breathing resulted in a significantly higher $\mathrm{F}_{\mathrm{IO}_{2}}$ than closed-mouth breathing with oxygen flows of 2 and $5 \mathrm{~L} / \mathrm{min}$ administered via a pharyngeal cannula. ${ }^{*} P<.05$.

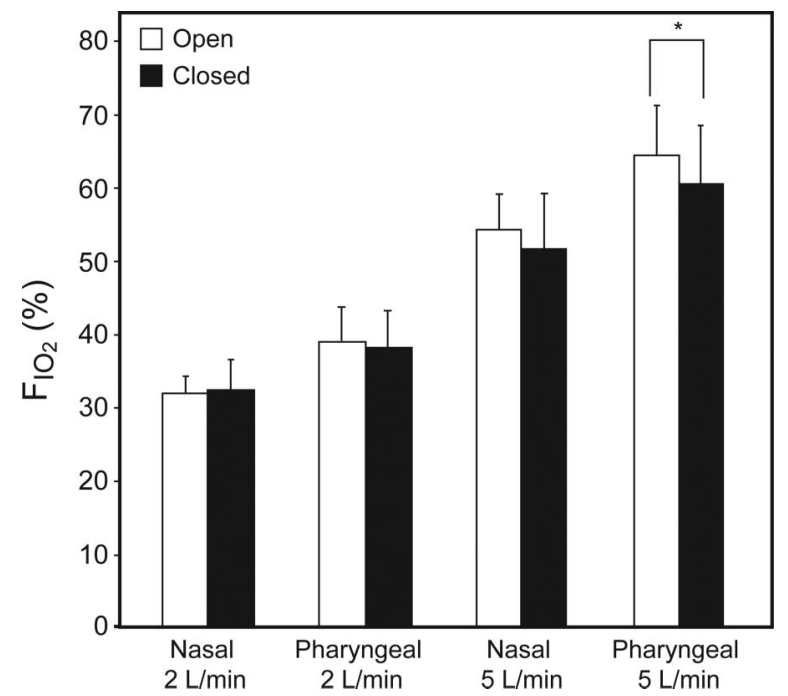

Fig. 10. Comparison between open- and closed-mouth breathing at a high tidal volume. Open-mouth breathing resulted in a significantly higher $\mathrm{F}_{\mathrm{IO}_{2}}$ than closed-mouth breathing with oxygen flows of 2 and $5 \mathrm{~L} / \mathrm{min}$ administered via a pharyngeal cannula. ${ }^{*} P<.05$.

the $\mathrm{F}_{\mathrm{IO}_{2}}$ by serving as an oxygen reservoir. The results of the present study seem to support the findings of previous studies. Open-mouth breathing results in a larger oral and pharyngeal space, which increases the size of the oxygen reservoir. Oxygen administration via a pharyngeal cannula might contribute to the oxygen reservoir formation.

It is commonly believed that the effectiveness of lowflow oxygen supply systems is affected by the patient's breathing pattern, which makes the actually delivered $\mathrm{F}_{\mathrm{IO}_{2}}$
Table 1. $\mathrm{F}_{\mathrm{IO}_{2}}$ at Each Setting

\begin{tabular}{|c|c|c|c|c|}
\hline Device & $\begin{array}{l}\text { Oxygen flow } \\
\text { (L/min) }\end{array}$ & $\begin{array}{l}\text { Position of } \\
\text { Mouth }\end{array}$ & $\begin{array}{c}\mathrm{V}_{\mathrm{T}} \\
(\mathrm{mL})\end{array}$ & $\begin{array}{c}\mathrm{F}_{\mathrm{IO}_{2}} \\
\text { (mean } \pm \mathrm{SD}\end{array}$ \\
\hline \multirow[t]{4}{*}{ Nasal cannula } & \multirow[t]{4}{*}{2} & \multirow[t]{2}{*}{ Open } & 350 & $0.32 \pm 0.02$ \\
\hline & & & 700 & $0.32 \pm 0.02$ \\
\hline & & \multirow[t]{2}{*}{ Closed } & 350 & $0.33 \pm 0.03$ \\
\hline & & & 700 & $0.32 \pm 0.04$ \\
\hline \multirow[t]{4}{*}{ Pharyngeal cannula } & \multirow[t]{4}{*}{2} & \multirow[t]{2}{*}{ Open } & 350 & $0.38 \pm 0.04$ \\
\hline & & & 700 & $0.39 \pm 0.05$ \\
\hline & & \multirow[t]{2}{*}{ Closed } & 350 & $0.36 \pm 0.04$ \\
\hline & & & 700 & $0.38 \pm 0.05$ \\
\hline \multirow[t]{4}{*}{ Nasal cannula } & \multirow[t]{4}{*}{5} & \multirow[t]{2}{*}{ Open } & 350 & $0.51 \pm 0.06$ \\
\hline & & & 700 & $0.54 \pm 0.05$ \\
\hline & & \multirow[t]{2}{*}{ Closed } & 350 & $0.49 \pm 0.06$ \\
\hline & & & 700 & $0.51 \pm 0.08$ \\
\hline \multirow[t]{4}{*}{ Pharyngeal cannula } & \multirow[t]{4}{*}{5} & \multirow[t]{2}{*}{ Open } & 350 & $0.63 \pm 0.06$ \\
\hline & & & 700 & $0.64 \pm 0.06$ \\
\hline & & \multirow[t]{2}{*}{ Closed } & 350 & $0.57 \pm 0.07$ \\
\hline & & & 700 & $0.61 \pm 0.08$ \\
\hline \multirow[t]{4}{*}{ Pharyngeal cannula } & \multirow[t]{4}{*}{10} & \multirow[t]{2}{*}{ Open } & 350 & $0.80 \pm 0.07$ \\
\hline & & & 700 & $0.78 \pm 0.07$ \\
\hline & & \multirow[t]{2}{*}{ Closed } & 350 & $0.79 \pm 0.09$ \\
\hline & & & 700 & $0.78 \pm 0.07$ \\
\hline
\end{tabular}

$\mathrm{V}_{\mathrm{T}}=$ tidal volume

unstable. ${ }^{4}$ In this study, we abolished this factor by fixing breathing pattern using a flow meter. With both nasal and pharyngeal cannulas, the magnitude of the $\mathrm{V}_{\mathrm{T}}$ had no significant influence on the $\mathrm{F}_{\mathrm{IO}_{2}}$. Contrary to our initial hypothesis that breathing pattern (including $\mathrm{V}_{\mathrm{T}}$ and frequency) might affect the $\mathrm{F}_{\mathrm{IO}_{2}}$ because of changes in dead space and the effect of rebreathing, our results suggested that breathing pattern might not influence oxygen delivery. Opioids tend to increase $\mathrm{V}_{\mathrm{T}}$ and decrease breathing frequency. ${ }^{5}$ On the other hand, benzodiazepines and propofol tend to decrease $V_{T}$ and increase breathing frequency. ${ }^{6,7}$ Our results seem to suggest that the choice of sedative drugs is not likely to significantly affect the $\mathrm{F}_{\mathrm{IO}_{2}}$ in sedated patients.

An oxygen flow of $10 \mathrm{~L} / \mathrm{min}$ administered via a pharyngeal cannula increased the $\mathrm{F}_{\mathrm{IO}_{2}}$ to as high as 0.80 . In addition, PEEP might be generated by the high flow of oxygen. ${ }^{11}$ Our results may find application in emergency situations of severe hypoxia, where $10 \mathrm{~L} / \mathrm{min}$ oxygen delivered via a pharyngeal cannula may prove to be an easy and helpful method for oxygenation.

This study has several limitations. First, the participants' respiratory dead spaces were enlarged by a volume equal to the area from the mannequin's pharyngeal space to the face mask. The volume of this space was at least $60 \mathrm{~mL}$. Dead space from the pharyngeal space of the mannequin to the face mask was significantly larger than the participants' actual dead space volume. 


\section{Effects of Breathing Pattern on Oxygen Delivery}

Second, although this study showed the efficacy of a pharyngeal cannula during procedural sedation, the fact that the pharyngeal cannula administers dry gases directly to the pharynx may be a problem. No humidifying devices (such as a bubble humidifier) was used in this study because those devices might not commonly be used in upper gastrointestinal endoscopy patients. Dry-gas administration can cause airway complications, such as ciliary dysfunction, airway injury, atelectasis, and pneumonia. ${ }^{12-14} \mathrm{~A}$ pharyngeal cannula may be slightly more invasive than a nasal cannula, and local adverse effects have not been evaluated. Hence, clinical evaluation is necessary to confirm the safety of oxygen administration via a pharyngeal cannula and the necessity of humidifying devices. The fraction of expired oxygen might affect the $\mathrm{F}_{\mathrm{IO}_{2}}$, but it was not measured in this study.

Another limitation of this study is that the mannequin breathed via both mouth and nose in open-mouth settings. In contrast, patients can breathe through their noses or mouths with their mouths open. We did not study the situation in which the mannequin breathed only through the mouth because it is inappropriate to evaluate the effect of oxygen supplementation via a nasal or pharyngeal cannula in such a setting.

\section{Conclusions}

A pharyngeal cannula provided a higher $\mathrm{F}_{\mathrm{IO}_{2}}$ than a nasal cannula at the same oxygen flow during open- and closed-mouth breathing in this study. Oxygen administration via a pharyngeal cannula rather than a nasal cannula might be clinically useful in sedated patients, who are likely to need a higher $\mathrm{F}_{\mathrm{IO}_{2}}$ to prevent severe hypoxia. The breathing pattern did not influence the $\mathrm{F}_{\mathrm{IO}_{2}}$ in this study.

\section{REFERENCES}

1. American Thoracic Society/European Respiratory Society Task Force. Standards for the diagnosis and management of patients with COPD. 2004. http://www.thoracic.org/go/copd. August 3, 2015.

2. Green ID. Choice of method for administration of oxygen. BMJ 1967;3(5565):593-596.

3. Markovitz GH, Colthurst J, Storer TW, Cooper CB. Effective inspired oxygen concentration measured via transtracheal and oral gas analysis. Respir Care 2010;55(4):453-459.

4. Wettstein RB, Shelledy DC, Peters JI. Delivered oxygen concentrations using low-flow and high-flow nasal cannulas. Respir Care 2005; 50(5):604-609.

5. Smart JA, Pallett EJ, Duthie DJ. Breath interval as a measure of dynamic opioid effect. Br J Anaesth 2000;84(6):735-738.

6. Denaut M, Yernault JC, De Coster A. Double-blind comparison of the respiratory effects of parenteral lorazepam and diazepam in patients with chronic obstructive lung disease. Curr Med Res Opin 1974;2(10):611-615.

7. Goodman NW, Black AM, Carter JA. Some ventilatory effects of propofol as sole anaesthetic agent. Br J Anaesth 1987;59(12):14971503.

8. O'Reilly Nugent A, Kelly PT, Stanton J, Swanney MP, Graham B, Beckert L. Measurement of oxygen concentration delivered via nasal cannulae by tracheal sampling. Respirology 2014;19(4):538-543.

9. Eastwood GM, Reeves JH, Cowie BS. Nasopharyngeal oxygen in adult intensive care-lower flows and increased comfort. Anaesth Intensive Care 2004;32(5):670-671.

10. Kory RC, Bergmann JC, Sweet RD, Smith JR. Comparative evaluation of oxygen therapy techniques. JAMA 1962;179:767-772.

11. Parke R, McGuinness S, Eccleston M. Nasal high-flow therapy delivers low level positive airway pressure. Br J Anaesth 2009;103(6): 886-890.

12. Chalon J, Loew DA, Malebranche J. Effects of dry anesthetic gases on tracheobronchial ciliated epithelium. Anesthesiology 1972;37(3): 338-343.

13. Chalon J, Patel C, Ali M, Ramanathan S, Capan L, Tang CK, Turndorf H. Humidity and the anesthetized patient. Anesthesiology 1979; 50(3): 195-198.

14. Gross JL, Park GR. Humidification of inspired gases during mechanical ventilation. Minerva Anestesiol 2012;78(4):496-502. 